\title{
Inhibition of Influenza Virus Polymerase by Interfering with
}

\section{Its Protein-Protein Interactions}

\author{
Serena Massari, ${ }^{\mathrm{a}^{*}}$ Jenny Desantis, ${ }^{\mathrm{b}}$ Maria Giulia Nizi, ${ }^{\mathrm{a}}$ Violetta Cecchetti, ${ }^{\mathrm{a}}$ Oriana Tabarrini. ${ }^{\mathrm{a}}{ }^{\mathrm{*}}$ \\ ${ }^{a}$ Department of Pharmaceutical Sciences, University of Perugia, 06123 Perugia Italy; \\ ${ }^{b}$ Department of Chemistry, Biology and Biotechnology, University of Perugia, 06123, Perugia \\ Italy. \\ * Address correspondence to these authors at the Department of Pharmaceutical Science, \\ University of Perugia, Via del Liceo 1, 06123 Perugia, Italy; For SM: Tel: +390755855134; E- \\ mail: serena.massari@unipg.it.For OT:Tel: +390755855139; E-mail, oriana.tabarrini@unipg.it.
}

Table of Contents

$\begin{array}{ll}\text { Figure S1. Binding pose of compounds 1-5 and 7-10 } & \text { S2 }\end{array}$

$\begin{array}{ll}\text { Figure S2. Binding pose of compounds } 6 & \text { S2 }\end{array}$

$\begin{array}{ll}\text { Figure S3. Binding pose of compound } 14 & \text { S3 }\end{array}$

$\begin{array}{ll}\text { Figure S4. Binding pose of compound } 15 & \text { S3 }\end{array}$

$\begin{array}{ll}\text { Figure S5. Binding pose of compound } 19 & \text { S4 }\end{array}$

Figure S6. Binding pose of compound $21 \quad$ S5

Figure S7. Binding pose of compound $23 \quad$ S5

Figure S8. Binding pose of an analogue of compound $\mathbf{3 2} \quad$ S6 

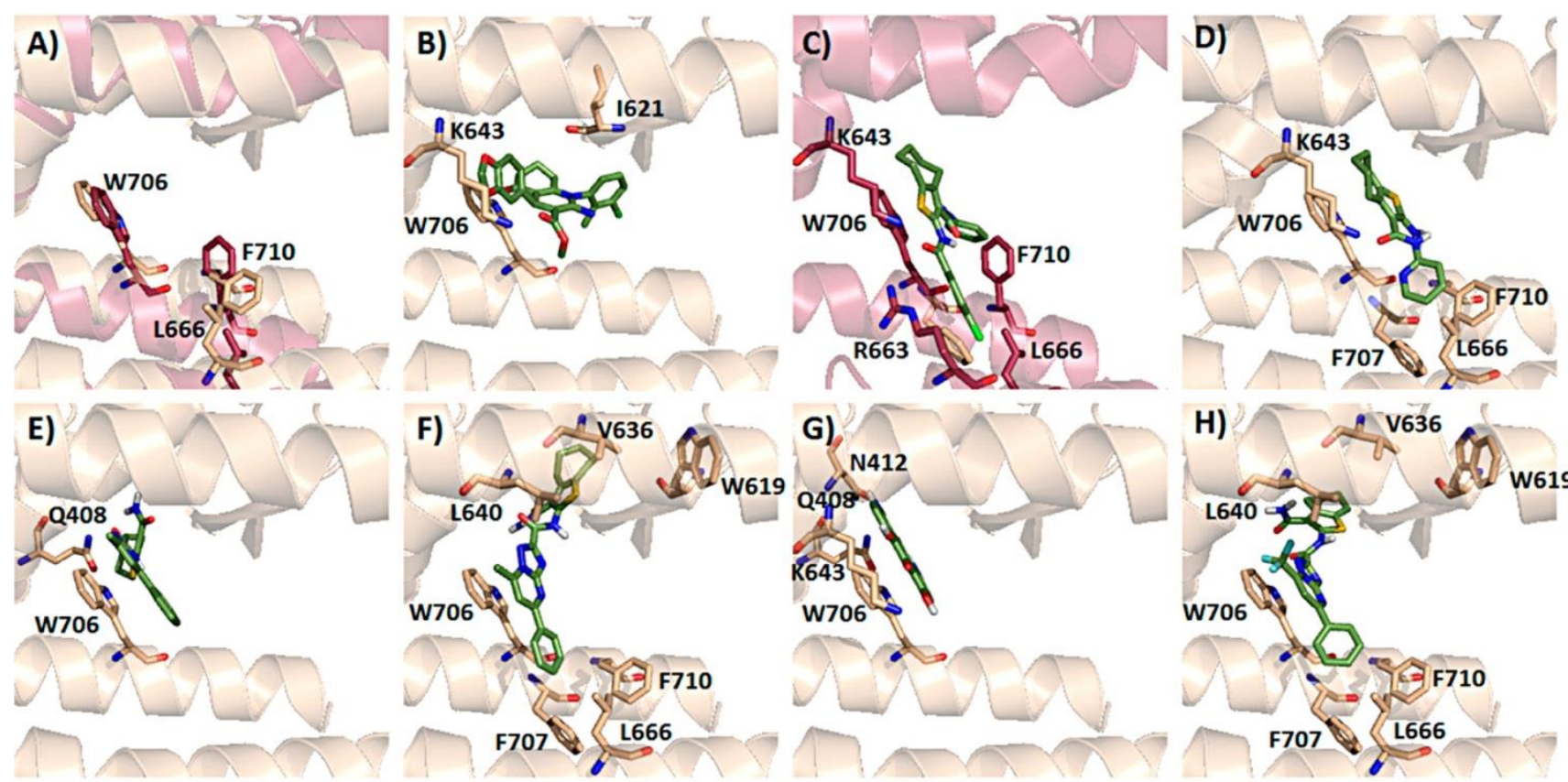

G)
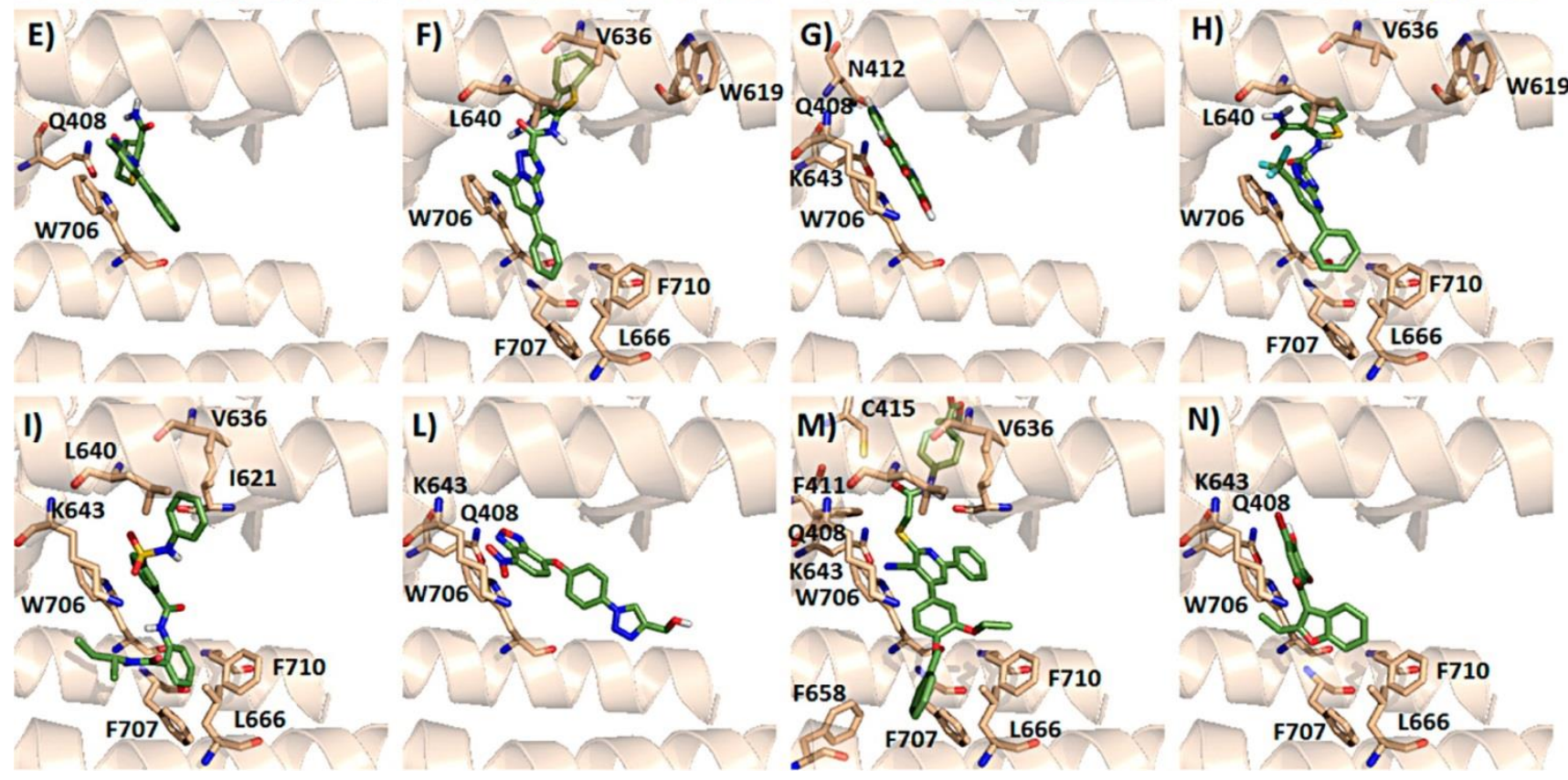

Figure S1. Key residues located in the PA cavity (A, pdb: 3CM8) and FLAP binding pose for compounds 1 (B), 2 (C), 3 (H), 4 (E), 5 (F), 7 (I), 8 (L), 9 (N), and 10 (G). (D) and (M) show the binding pose for two compounds not mentioned in this review. Reproduced from [Massari, S. Goracci, L.; Desantis, J.; Tabarrini, O. Polymerase Acidic Protein-Basic Protein 1 (PA-PB1) Protein-protein interaction as a target for next-generation anti-influenza therapeutics. J. Med. Chem. 2016, 59, 7699-7718]. ${ }^{1}$ Copyright [2016] American Chemical Society.

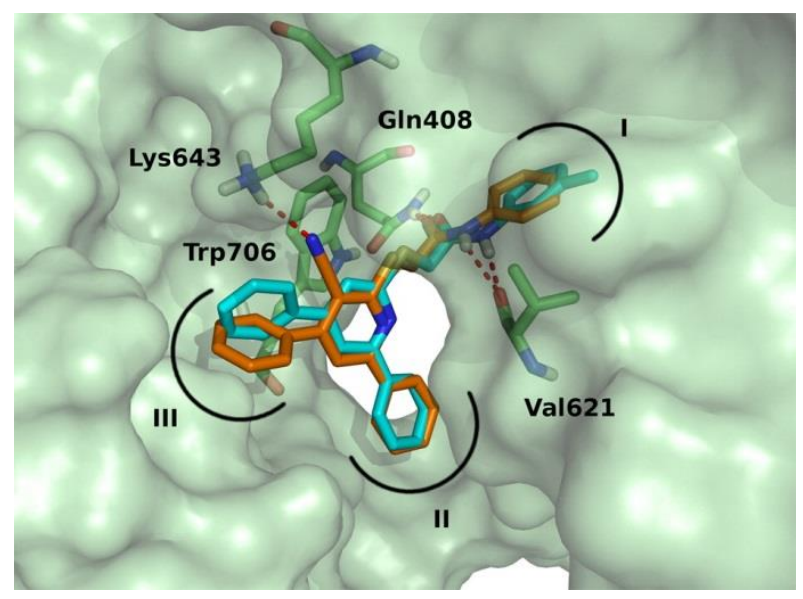


Figure S2. Docking pose for compound 6 (cyan sticks) within the PAc (pdb: from docking simulations. Reproduced from [Trist, I. M.; Nannetti, G.; Tintori, C.; Fallacara, A. L.; Deodato, D.; Mercorelli, B.; Palù, G.; Wijtmans, M.; Gospodova, T.; Edink, E.; Verheij, M.; de Esch, I.; Viteva, L.; Loregian, A.; Botta, M. 4,6-Diphenylpyridines as promising novel anti-influenza agents targeting the PA-PB1 protein-protein interaction: structure-activity relationships exploration with the aid of molecular modeling. J. Med. Chem. 2016, 59, 2688-26703]. ${ }^{2}$ Copyright [2016] American Chemical Society.
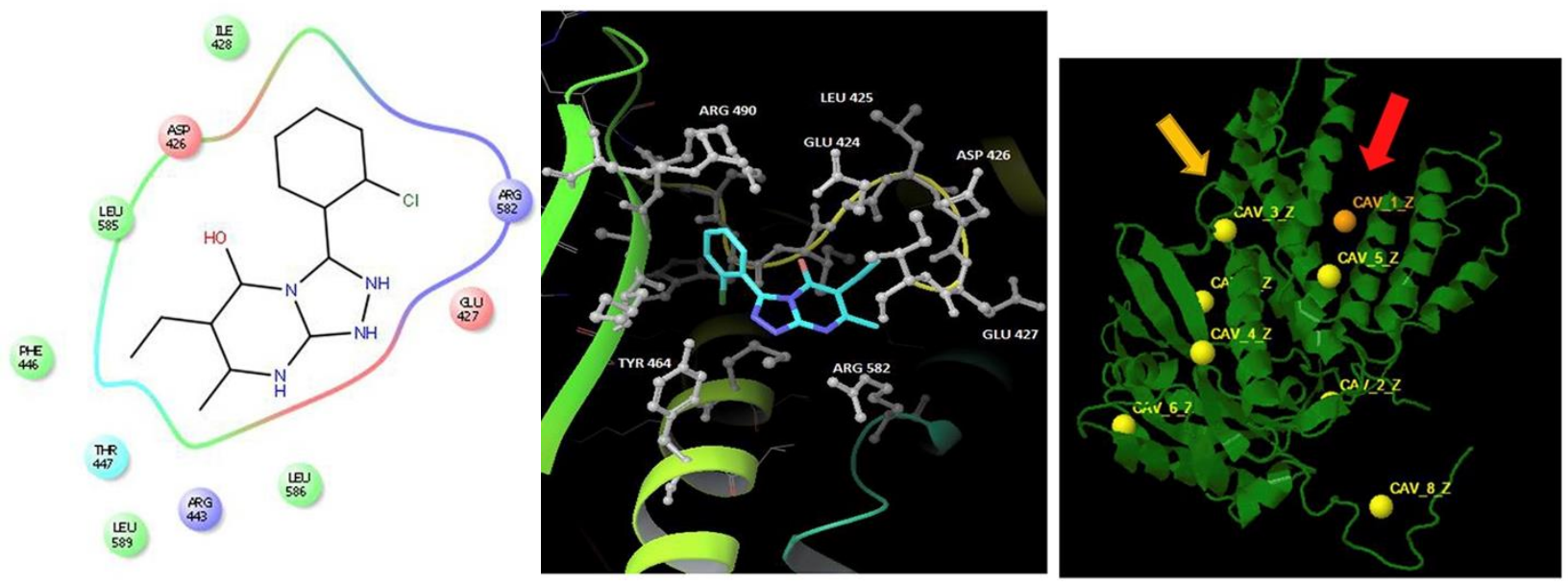

Figure S3. Docking pose for compound 14 (left and center) and binding site of compound 14 (yellow arrow) and PB1 binding site (red arrow) (right) within the PA $\mathrm{C}_{\mathrm{C}}$ (pdb: 3CM8). Reproduced with permission from [Yuan, S.; Chu, H.; Zhao, H.; Zhang, K.; Singh, K.; Chow, B. K. C.; Kao, R. Y. T.; Zhou, J.; Zheng, B.-J. Identification of a small-molecule inhibitor of influenza virus via disrupting the subunits interaction of the viral polymerase. Antiviral Res. 2016, 125, 34-42.] $]^{3}$ Copyright [2015] Elsevier B.V.
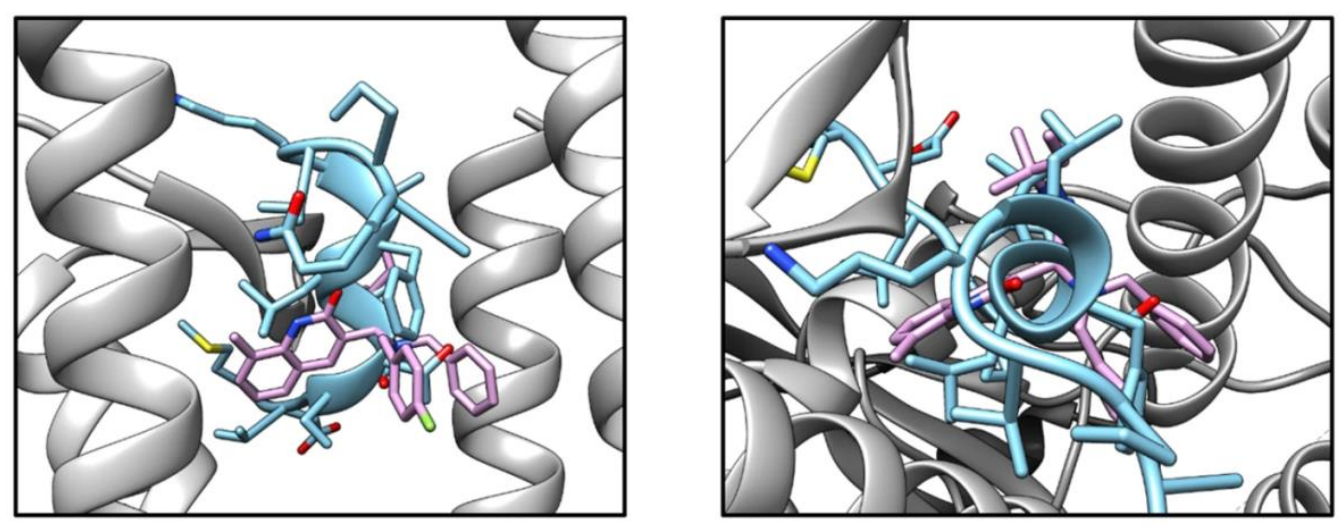
Figure S4. Docking pose for compound 15 within the PA $A_{C}$ based on in silico calculations, side view (left) and top view (right); crystal structure of PA (pdb: 2ZNL, grey) in complex with PB1 (light blue) and binding structure of compound 15 (pink) from docking simulation were overlaid. Reproduced with permission from [Watanabe, K.; Ishikawa, T.; Otaki, H.; Mizuta, S.; Hamada, T.; Nakagaki, T.; Ishibashi, D.; Urata, S.; Yasuda, J.; Tanaka, Y.; Nishida, N. Structure-based drug discovery for combating influenza virus by targeting the PA-PB1 interaction. Sci. Rep. 2017, 7 (1), 9500.] ${ }^{4}$ Copyright [2017] Springer Nature.

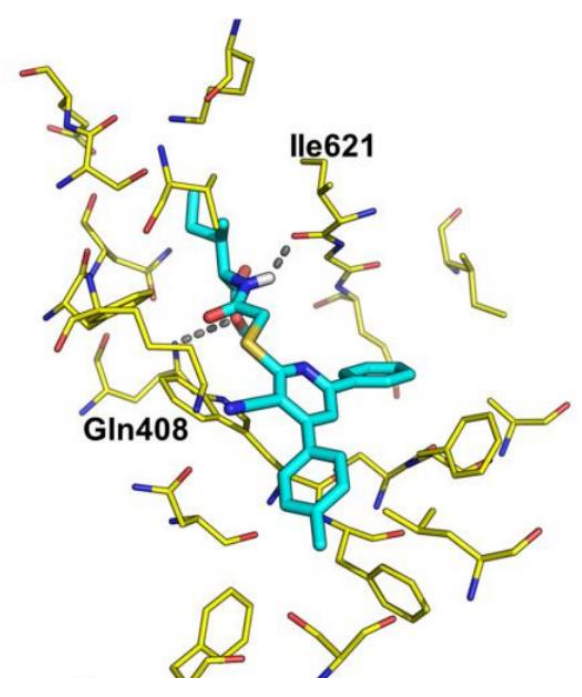

Figure S5. Docking pose for compound 19 (cyan stick). The crystallographic structure of PA in complex with PB1 (pdb: 4WSB) is shown as yellow lines. Polar interactions are highlighted by grey dashed lines. Only residues within $4 \AA$ from the ligands are showed; non-polar $\mathrm{H}$ atoms are omitted. Reproduced with permission from [D’Agostino, I.; Giacchello, I.; Nannetti, G.; Fallacara, A. L.; Deodato, D.; Musumeci, F.; Grossi, G.; Palù, G.; Cau, Y.; Trist, I. M.; Loregian, A.; Schenone, S.; Botta, M. Synthesis and biological evaluation of a library of hybrid derivatives as inhibitors of influenza virus PA-PB1 interaction. Eur. J. Med. Chem. 2018, 157, 743-758]. ${ }^{5}$ Copyright [2018] Elsevier Masson SAS. 

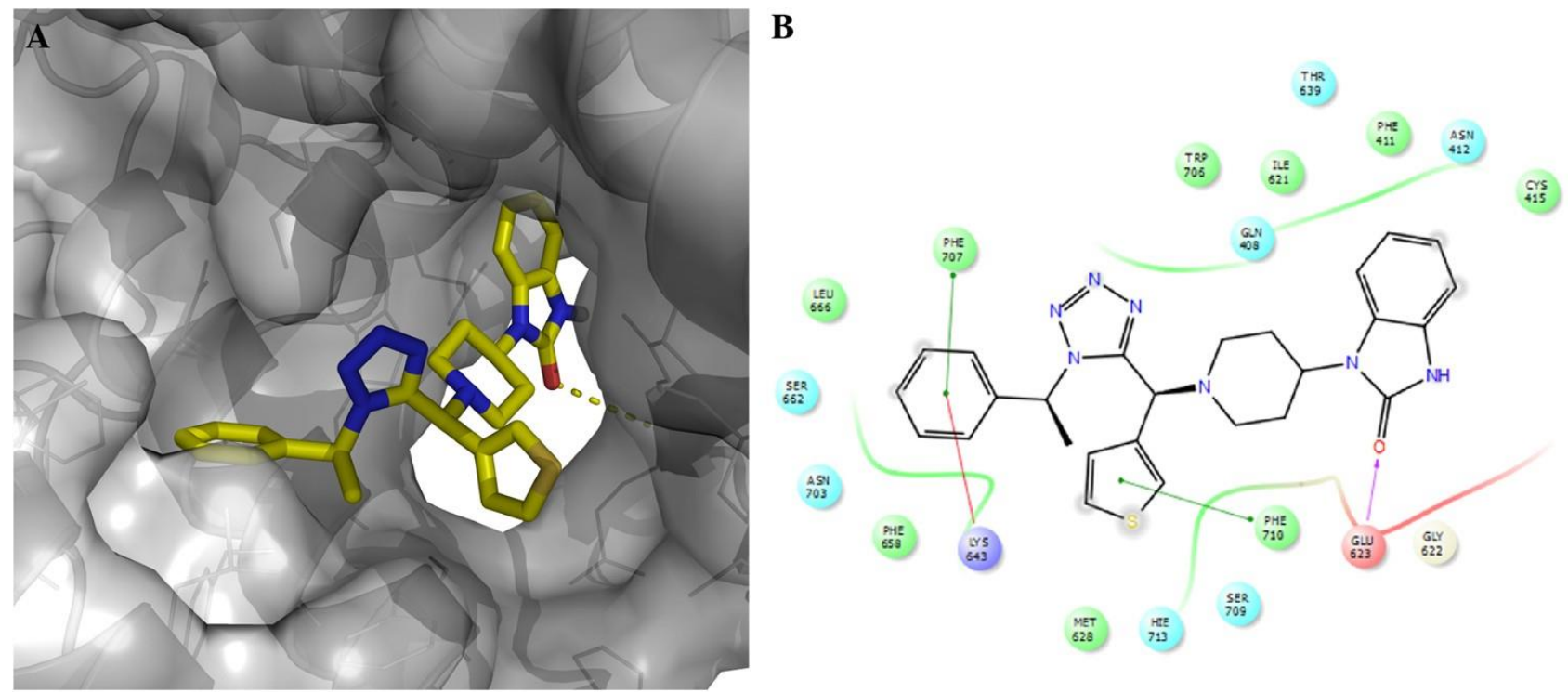

Figure S6. Surface view of docking pose for compound 21 in the PB1 $1_{N}$-binding pocket in PAC (A) and its ligand interaction diagram with residues in the binding site (B). Reproduced with permission from [Zhang, J.; Hu, Y.; Foley, C.; Wang, Y.; Musharrafieh, R.; Xu, S.; Zhang, Y.; Ma, C.; Hulme, C.; Wang, J. Exploring Ugi-azide four-component reaction products for broad-spectrum influenza antivirals with a high genetic barrier to drug resistance. Sci. Rep. 2018, 8 (1), 4653]. ${ }^{6}$ Copyright [2018] Springer Nature.

A

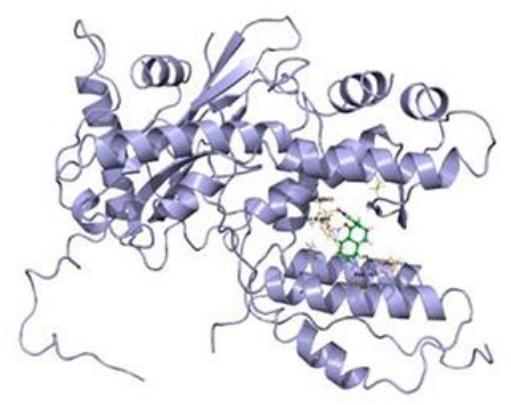

B

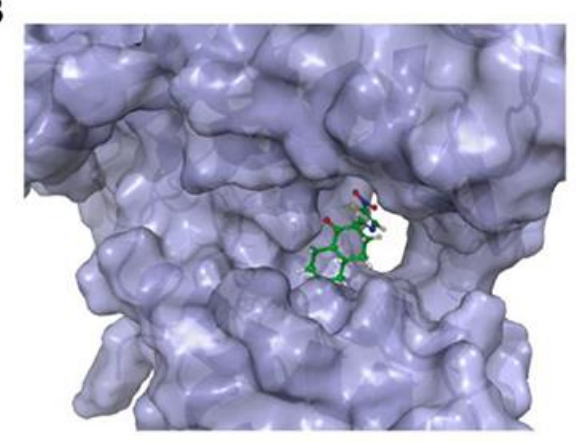

C

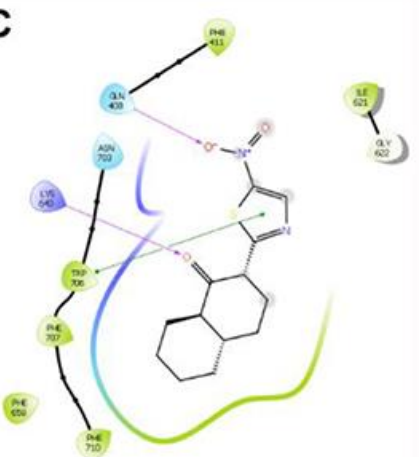

Figure S7. Best docking pose of compound 23 in PAC cavity from PA-PB1 complex (pdb: 3CM8) (A), its surface view (B) and its ligand interaction diagram (C). Reproduced from [Zhang, J.; Hu, Y.; Wu, N.; Wang, J. Discovery of influenza polymerase PA-PB1 interaction inhibitors using an in vitro split-luciferase complementation-based assay. ACS Chem. Biol. 2020, 15 (1), 74-82]. ${ }^{7}$ Copyright [2020] American Chemical Society. 

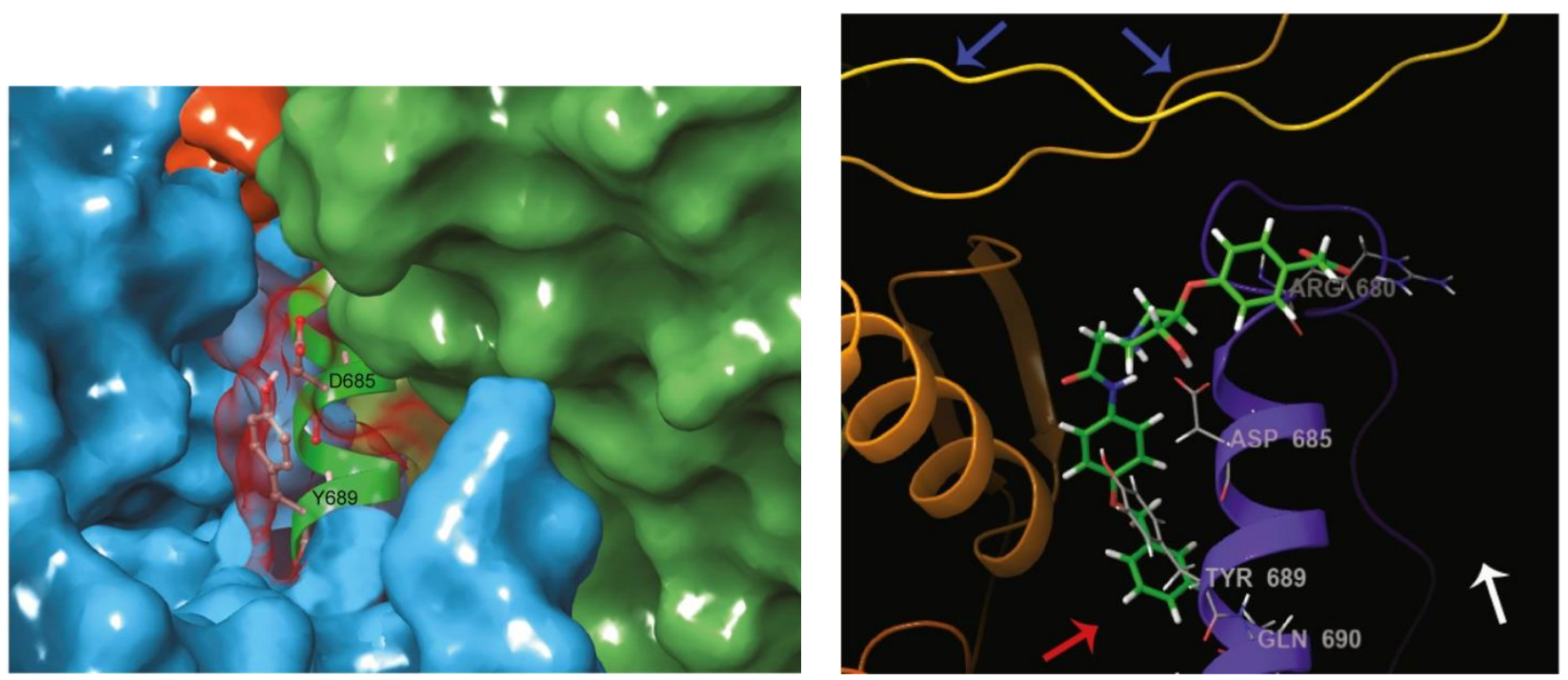

Figure S8. Proposed binding site of compound 5 (original number reported in the manuscript by Mohl et al., structure is reported below), a strict analogue of compound 32 (left): PA-PB1 complex (pdb: 4WSB, blue surface) in complex with RanBP5 homologue Kap121p (pdb: 3W3Z, green surface) and key residues D685 and Y689 of PB1 anchor helix (transparent red surface); view of the binding site of compound 5 docked (right): the bipartite NLS (blue arrows), RanBP5 binding interface (white arrow), and PB2 binding site (red arrow). Reproduced with permission from [Mohl, G., Liddle, N., Nygaard, J., Dorius, A., Lyons, N., Hodek, J., Weber, J., Michaelis, D. J., and Busath, D. D. (2019) Novel influenza inhibitors designed to target PB1 interactions with host importin RanBP5. Antiviral Res. 164, 81-90]. ${ }^{8}$ Copyright [2019] Elsevier B.V.<smiles>O=C(O)Cc1ccc(OC2CN(CC(=O)Nc3ccc(OCc4ccccc4)cc3)C[C@H]2O)cc1</smiles> 


\section{References}

(1) Massari, S.; Nannetti, G.; Desantis, J.; Muratore, G.; Sabatini, S.; Manfroni, G.; Mercorelli, B.; Cecchetti, V.; Palù, G.; Cruciani, G.; Loregian, A.; Goracci, L.; Tabarrini, O. A Broad Anti-Influenza Hybrid Small Molecule That Potently Disrupts the Interaction of Polymerase Acidic Protein-Basic Protein 1 (PA-PB1) Subunits. J. Med. Chem. 2015, 58, 3830-3842. https://doi.org/10.1021/acs.jmedchem.5b00012.

(2) Trist, I. M. L.; Nannetti, G.; Tintori, C.; Fallacara, A. L.; Deodato, D.; Mercorelli, B.; Palù, G.; Wijtmans, M.; Gospodova, T.; Edink, E.; Verheij, M.; De Esch, I.; Viteva, L.; Loregian, A.; Botta, M. 4,6-Diphenylpyridines as Promising Novel Anti-Influenza Agents Targeting the PA-PB1 Protein-Protein Interaction: Structure-Activity Relationships Exploration with the Aid of Molecular Modeling. J. Med. Chem. 2016, 59, 2688-2703. https://doi.org/10.1021/acs.jmedchem.5b01935.

(3) Yuan, S.; Chu, H.; Zhao, H.; Zhang, K.; Singh, K.; Chow, B. K. C.; Kao, R. Y. T.; Zhou, J.; Zheng, B.-J. Identification of a Small-Molecule Inhibitor of Influenza Virus via Disrupting the Subunits Interaction of the Viral Polymerase. Antiviral Res. 2016, 125, 34-42. https://doi.org/10.1016/j.antiviral.2015.11.005.

(4) Watanabe, K.; Ishikawa, T.; Otaki, H.; Mizuta, S.; Hamada, T.; Nakagaki, T.; Ishibashi, D.; Urata, S.; Yasuda, J.; Tanaka, Y.; Nishida, N. Structure-Based Drug Discovery for Combating Influenza Virus by Targeting the PA-PB1 Interaction. Sci. Rep. 2017, 7, 95009512. https://doi.org/10.1038/s41598-017-10021-w.

(5) D’Agostino, I.; Giacchello, I.; Nannetti, G.; Fallacara, A. L.; Deodato, D.; Musumeci, F.; Grossi, G.; Palù, G.; Cau, Y.; Trist, I. M.; Loregian, A.; Schenone, S.; Botta, M. Synthesis and Biological Evaluation of a Library of Hybrid Derivatives as Inhibitors of Influenza Virus PA-PB1 Interaction. Eur. J. Med. Chem. 2018, 157, 743-758.

https://doi.org/10.1016/j.ejmech.2018.08.032.

(6) Zhang, J.; Hu, Y.; Foley, C.; Wang, Y.; Musharrafieh, R.; Xu, S.; Zhang, Y.; Ma, C.; Hulme, 
C.; Wang, J. Exploring Ugi-Azide Four-Component Reaction Products for Broad-Spectrum Influenza Antivirals with a High Genetic Barrier to Drug Resistance. Sci. Rep. 2018, 8, 4653-4667. https://doi.org/10.1038/s41598-018-22875-9.

(7) Zhang, J.; Hu, Y.; Wu, N.; Wang, J. Discovery of Influenza Polymerase PA-PB1 Interaction Inhibitors Using an in Vitro Split-Luciferase Complementation-Based Assay. ACS Chem. Biol. 2020, 15, 74-82. https://doi.org/10.1021/acschembio.9b00552.

(8) Mohl, G.; Liddle, N.; Nygaard, J.; Dorius, A.; Lyons, N.; Hodek, J.; Weber, J.; Michaelis, D. J.; Busath, D. D. Novel Influenza Inhibitors Designed to Target PB1 Interactions with Host Importin RanBP5. Antiviral Res. 2019, 164, 81-90.

https://doi.org/10.1016/j.antiviral.2019.02.003. 